\title{
www.medigraphic.org.mx
}

Acta Ortopédica Mexicana 2018; 32(5): Sep.-Oct: 303

\section{Utilidad de la ciencia que nunca se ha citado}

\author{
Sandoval-Gutiérrez JL* \\ Instituto Nacional de Enfermedades Respiratorias «Ismael Cosío Villegas»
}

El Dr. Encalada Díaz ${ }^{1}$ expone un editorial interesante sobre los problemas de los artículos que, aunque publicados, nunca son citados.

Es importante recordar que las personas que utilizan su tiempo para hacer un trabajo de investigación, generalmente el objetivo primario de la misma es la culminación y su publicación, el que se cite es una aspiración generalmente de las personas que se dedican a la investigación, en México por ejemplo se necesitan los obligados puntos para la permanencia o promoción en el Sistema Nacional de Investigadores (SNI).

Muchas revistas internacionales usan como candado un número limitado de figuras, tablas $y$ referencias para su publicación, lo que hace que el autor tenga por necesidad el no incluir mucha literatura científica leída, pero que no encuentra su lugar en la bibliografía.

Es importante mencionar que, para el clínico, muchos artículos denominados de bajo impacto como revisiones, monografías, serie de casos o inclusive reporte de caso, son de alta relevancia para su formación y mejor atención a los pacientes; es lo que se puede denominar Factor de Impacto Clínico. ${ }^{2}$

Así como en el mundo editorial la mayoría de los libros no son los más vendidos (best sellers) o ganan premios, no todos los artículos académicos deben ser citados en los próximos cinco años, ya que los mismos pueden ser referentes a futuro.

Haciendo una analogía están las experiencias de grandes literatos como Octavio Paz y Jorge Luis Borges donde sus obras de ediciones de tan sólo 1,000 copias tardaban hasta más de una década en ser vendidas, por lo tanto, no leídas y menos citadas.

Así como en el arte, la ciencia tiene sus tiempos, dejemos que el mismo permita la adecuada maduración de los trabajos científicos.

Recordemos el primer aforismo hipocrático:

«La vida es corta y el arte requiere mucho tiempo para ser aprendido. La oportunidad se va fácilmente, el empirismo es peligroso e inconveniente y el razonamiento difícil.» ${ }^{3}$

Bibliografía

1. Encalada-Díaz MI. The science that has never been cited. Acta Ortop Mex. 2018; 32(1): 1.

2. Sandoval-Gutiérrez JL. Clinical impact factor: can it be measured? Rev Med Inst Mex Seguro Soc. 2018; 56(1): 53.

3. Hipócrates aforismos. 4a edición. Ed. PREMIA; Madrid, 1983.

\footnotetext{
* Neumólogo-Intensivista. Doctorado en Investigación Médica. Instituto Nacional de Enfermedades Respiratorias «Ismael Cosío Villegas».

Dirección para correspondencia:

Dr. José Luis Sandoval-Gutiérrez

E-mail: sandovalgutierrez@gmail.com

Este artículo puede ser consultado en versión completa en http:// www.medigraphic.com/actaortopedica
} 